\title{
Use of Digital Technological Tools among Undergraduate English Language Learners in Pakistan
}

\author{
Maheen Tufail Dahraj ${ }^{1}$, Hina Manzoor ${ }^{1} \&$ Mahnoor Tufail $^{2}$ \\ 1 Department of Humanities, NED University of Engineering and Technology, Karachi, Pakistan \\ 2 Department of Communication, Institute of Business Management, Karachi, Pakistan \\ Correspondence: Hina Manzoor, Department of Humanities, NED University of Engineering and Technology, \\ Karachi, Pakistan. E-mail: hinam@neduet.edu.pk
}

Received: February 12, 2020

Accepted: April 2, 2020

Online Published: April 28, 2020

doi:10.5539/ijel.v10n4p61

URL: https://doi.org/10.5539/ijel.v10n4p61

\begin{abstract}
Technology has become an important source for enhancing the knowledge of the students. Apart from the non-academic purposes, the use of technology for the academic purposes also has greater impact on the process of learning specifically on tertiary education. Therefore, it has become essential for higher education institutions to focus on the available opportunities for integrating technology in the academic setting. The developing countries like Pakistan, however; are facing some major challenges in technology integration due to the unavailability of sufficient financial resources. Hence, this study explores the use of digital technological tools at undergraduate level in one of the public sector universities of Pakistan. The study also examines the impact of the medium of instruction and respective discipline of the tertiary level students on the use of technology. For this purpose, an online survey was conducted from 200 undergraduate students studying in four different disciplines in the university. The findings revealed that the majority of the students at the undergraduate level have accessibility to smartphones, laptops or desktop computers in the university but only a few students use these available technological tools for learning purposes. Smartphones were determined to be the most easily available technological tool while the students generally do not prefer carrying their laptops to the university. Besides this, the students also reported having limited technological knowledge and skills for the digital tools to be used for educational and learning purposes. However, a greater percentage of the students were willing to participate in training sessions for learning.
\end{abstract}

Keywords: language learning, digital technology, smartphones, educational institutions

\section{Introduction}

\subsection{Technology in Educational Setting}

Technology is now increasingly used in an educational environment and the technological practices and perceptions of students regarding technology in educational practices have been studied by many researchers. According to Bolluyt (2014), Laptops and mobile phones were observed to be the most commonly used digital devices by the students at tertiary education and the tablets, however, were found with the widespread accessibility to technology in different settings. Technology plays an important role in facilitating self-directed learning as well as learning while collaborating and connecting with the other learners. Incorporation of technology in classrooms is also contributing to bring improvement in learning, however; there is still a necessity of searching for the best ways following which the technology can be utilised for improving the educational outcomes and experiences of the students (Dahlstrem \& Bichsel, 2014). The educational institutions are facing severe challenges in increasing the level of engagement of the students through the application of such technologies that do not only contribute to the fulfilment of educational needs but, at the same time, also enhance their educational outcomes. For making further decisions regarding the introduction of technology, higher authorities should provide the necessary support to the students as it is essential to consider the available technological practices and environment for learning purposes (Dahlstrem \& Bichsel, 2014).

Gosper, Malfroy and McKenzie (2013), Dahlstrom and Bichsel (2016), Swanson and Walker (2015) have also reported that the technologies are incorporated for both academic and non-academic purposes but in a different manner. For instance, e-mail in the USA is generally preferred for non-academic purposes while social media 
networking for academic purposes (Swanson \& Walker, 2015). On the other hand, online libraries and learning management systems are considered suitable for academic purposes by the students in Australia (Gosper, Malfroy, \& McKenzie, 2013). Besides this, Deng and Tavares (2015) identified that Moodle is considered to be the most preferable academic platform by the students in Hong Kong.

The perceptions of the students regarding information and communication technology are only determined in the studies conducted for the developed countries in the world. In comparison to the developing and least developed countries with 67 and 30 percent of youngsters between 15 to 24 years of age, $94 \%$ of the younger population in developed countries is using the internet (ITU, 2017). These researches have indicated that ICT infrastructure and facilities, in developing countries are limited. In Pakistan, only a few studies have focused on educational context and especially on the use of social networking sites. However, research on the use of technology in the educational context in Pakistan is still neglected (Rai, Hussain, \& Zaheer, 2016). Pakistan is a developing country that occupies $142^{\text {nd }}$ position among total 166 economies according to the Global ICT index (Baloch, 2014). The digital practices in a country are not only influenced by socioeconomic factors and demographic factors such as gender, age, education, experience, skills and etc. (Geana \& Greiner, 2011; Antonio \& Tuffley, 2014).

The researches on ICT in developing countries have determined that digital devices are more easily accessible to men in comparison to women. Although significant efforts have been made to ensure equal accessibility of the digital technological tools but the gender gap still remains the same (Bogdan-Martin, 2016; Singh, 2017). The gender gap that was observed to be $11 \%$ in 2013 has increased to $12 \%$ in 2017 (ITU, 2017). In a study conducted by Pew Research Centre 2015, 13\% gender gap in using digital tools was found. Furthermore, the gender inequality index by the World Economic Forum (2016) has shown a huge gender gap in accessibility to the digital technology in Pakistan ranking 143 out of a total of 144 countries.

Out of total 7000 languages spoken by the people all around the world, there are only a few digital content languages. Therefore, the preferences of the students regarding technology and their experiences have also been shaped by the content language of technology. Digital technological tools serve as a major issue in getting access to the internet for both inexperienced users as well as those willing to access i.e., new users (Bolluyt, 2014). English, being the most spoken language, is used as a content language in $53.6 \%$ of online services, applications and websites. On the other hand, although Urdu is one of the official languages of Pakistan but it is only used in $0.1 \%$ of applications or websites (W3Techs, 2017).

Only $10 \%$ of the total population in Pakistan has access to the internet while there are only a few people who are familiar with English as the second language. The internet, in Pakistan, is preferably used by the population aged between 20 to 24 years; those studying at the tertiary educational institutions. The two major types of schools in Pakistan, as revealed by the Ministry of Education, Training and Standards in Higher Education (2014) are public and private sector schools with two major streams of education as English-medium and Urdu-medium. Most of the private schools are generally English-medium schools that offer special classroom facilities, qualified teachers with high-quality educational material and digital tools such as digital libraries, projectors etc. Therefore, private schools are preferred by families with higher living standards (Khurshid, Shah, \& Reid, 2016). Besides this, the students in Urdu medium schools generally have no access to the digital tools in schools, rather they rely on their personal access at home (Salam, Jianqiu, Pathan, \& Lei, 2017). It is important to note that the majority of the schools in Pakistan are Urdu-medium schools.

The impact of using mobile phones on the digital division in the developed countries has been investigated by a number of researchers (Mascheroni \& Olafsson, 2015). Puspitasari and Ishii (2016) have investigated that increased use of mobile technologies is expected to overcome the digital gap in developing countries as well. On the other hand, the researchers have also explored the benefits of using mobile technology for educational purposes, especially in making students familiar with the English language (Mueller, Wood, \& Archer, 2011).

Within the past few years, a rapid increase in the popularity of smartphones has been observed in Pakistan with the usage to be reaching at least 40 million in 2016 (The Nation, 2016). Considering the previously conducted researches, this study determines the students' use of digital technological tools at undergraduate level in one of the public sector universities in Pakistan for educational purposes. As only a few researches in Pakistan have been carried out for the purpose of exploring the role of the digital technological tools in facilitating English language learning. The present study also explores if the students prefer using digital technological tools for learning English language and for determining and gaining insight into the stated problem, the data has been collected using the student's previous practices. 


\subsection{Research Question}

The study focuses on the following research question:

What are the digital technological tools used by the undergraduate students in English language classroom at a public sector university in Pakistan?

\subsection{Research Objective}

To explore the digital technological tools used by the undergraduate students in English language classroom at a public sector university in Pakistan.

\section{Method}

An online survey was conducted from 200 students belonging to four departments of a university operating in the public sector in Pakistan. All the information was provided to the students participating in the research through electronic means. The initial part of the survey comprised of questions to be answered with either a yes or no further ensuring that the respondents can ask questions for their confirmation and for receiving a full explanation of the study. During the consent process, it was ensured that the students understand the necessity of their agreement as essential for taking part in the study.

Hence, the initial part of the survey was based on seeking respondents' consent followed by the actual questions related to the study. The Digital Practices Survey was developed in consideration with the survey form constructed by Gosper et al. (2013) called Student Experiences and Expectations of Technology (SEET) survey. The SEET survey comprises of 127 questions that are further arranged in five different sections exploring the use of at least 20 technologies for educational and social purposes, the experience and future preferences of the students regarding the use of digital devices and the learning management systems.

In this way, the survey was conducted for the identification of technology that is being used for educational purposes, for communicating with the students and teachers and for determining the extent to which mobile phones can facilitate in improving the use of English language for educational purposes. The SEET online survey, by Gosper et al. (2013), involved both undergraduate and postgraduate students in three universities in Australia. The survey, however, did not consider the differences in education systems as well as the technological use in Pakistan and Australia; therefore, it was observed not to be completely applicable for the present study. Consequently, in consideration of the aim of the study, several additions and modifications were made. The changes included removing digital tools that are not commonly used in Pakistan and adding a separate section regarding students' use of digital technological tools in language learning classroom.

The survey for the study included a total of 120 questions comprising both close and open-ended, yes/no and multiple-choice questions divided into five different sections. Furthermore, a four-point Likert scale is used for measuring the frequency of the usage of technologies by the students. The Likert scale comprised of: never or seldom, sometimes within a month, sometimes within a week, once or twice a day. Besides this, the future preferences of the students have been determined using another three-point Likert scale comprising of Yes, No and Yes I would prefer taking part in training sessions. The overall internal consistency and reliability were measured calculating Cronbach's Alpha with 0.95 of its value indicating the reliability of the instrument.

Among the five sections, the first section comprised of the survey and consent information. The second section included the demographic and background information such as gender, age, language, education and semester they are enrolled in and their medium of education. Self-evaluation of the English language skills of the students and their access to the technological devices for their studies was also sought. The questions regarding the access and usage of digital technological tools were also included. The third part included questions for determining the degree to which technology has been used for academic purposes and specifically in classrooms of English language. For the determination of the ways of communication with other students and teachers, instant text messages, emails, phone calls and other social networking sites such as Facebook were given as the options.

Besides that, the fourth section included questions regarding the usage of smartphones for improving English language skills including vocabulary, speaking, listening, reading and writing. The value of Cronbach's Alpha for the third and fourth sections is 0.92 and 0.93 respectively. The last section comprised of five questions regarding the determination and willingness of the students for participating in learners' training in using the digital technological tools along with a question asking permission for using the provided information for publications. The survey instrument was also tested on 10 students belonging to the English department of the same university. 


\subsection{Respondents}

The respondents of the present study were the undergraduate students studying in four different disciplines at a public sector university. The target population selection criterion was the completion of at least 12 years of education.

\subsection{Sampling Procedure and Size}

The sample size of 200 students comprised of 50 percent male and 50 percent female with their ages ranging between $17-25$ years. Out of which, $62 \%$ of the total sample population responded that Urdu is their first language followed by $25 \%$ Sindhi and $13 \%$ Punjabi. English was not determined to be the first language of any of the selected respondents. Besides this, the respondents were taken from the students studying in the first semester till fifth semester with four majors namely Management Sciences, Computer Sciences, Mechanical Engineering and English Linguistics.

Table 1. No. of Respondents from each selected discipline

\begin{tabular}{llll}
\hline Major Subjects & Male & Female & Total \\
\hline English Linguistics & 5 & 25 & 30 \\
Management Sciences & 20 & 25 & 45 \\
Computer Sciences & 25 & 40 & 65 \\
Mechanical Engineering & 50 & 10 & 60 \\
Total & 100 & 100 & 200 \\
\hline
\end{tabular}

The students who participated in the research were also asked regarding the type of school they studied as the medium of education. The table below indicates the number of respondents who studied in public and private sector English and Urdu medium schools before university.

Table 2. No. of respondents from each medium of education in public and private schools

\begin{tabular}{llll}
\hline Medium of Education in School & Public & Private & Total \\
\hline Urdu Medium & 87 & 40 & 127 \\
English Medium & 56 & 17 & 73 \\
\hline
\end{tabular}

The students were also asked regarding the number of years they have spent in studying English as a language. Around $36 \%$ of the students responded that they have spent 12 years or more, $47 \%$ had spent 5 to 11 years while the remaining $17 \%$ spent less than five years in studying the English language.

\subsection{Findings}

The findings of this research have been reported and arranged in consideration with three independent variables namely: gender, medium of education in schools and discipline they were associated within the university.

\section{Results}

The findings of the study are stated concerning the use of digital technological tools by the undergraduate students for learning English language at the public sector university in Pakistan.

\subsection{Student's Accessibility to the Technological Tools}

For the determination of the available and accessible technological tools, the students were asked to mention their preferences. After careful consideration of the technological tools in Pakistan, the major five tools that were included in the survey were smartphone, tablet, and availability of desktop computer at home or laptop, computers provided by the university in labs and libraries and bringing one's own laptop to the university. The access to the digital tools, as reported by the undergraduate students, is represented in Figure 1 below. The results indicated that the smartphone is the most easily accessible digital tool for the students. 


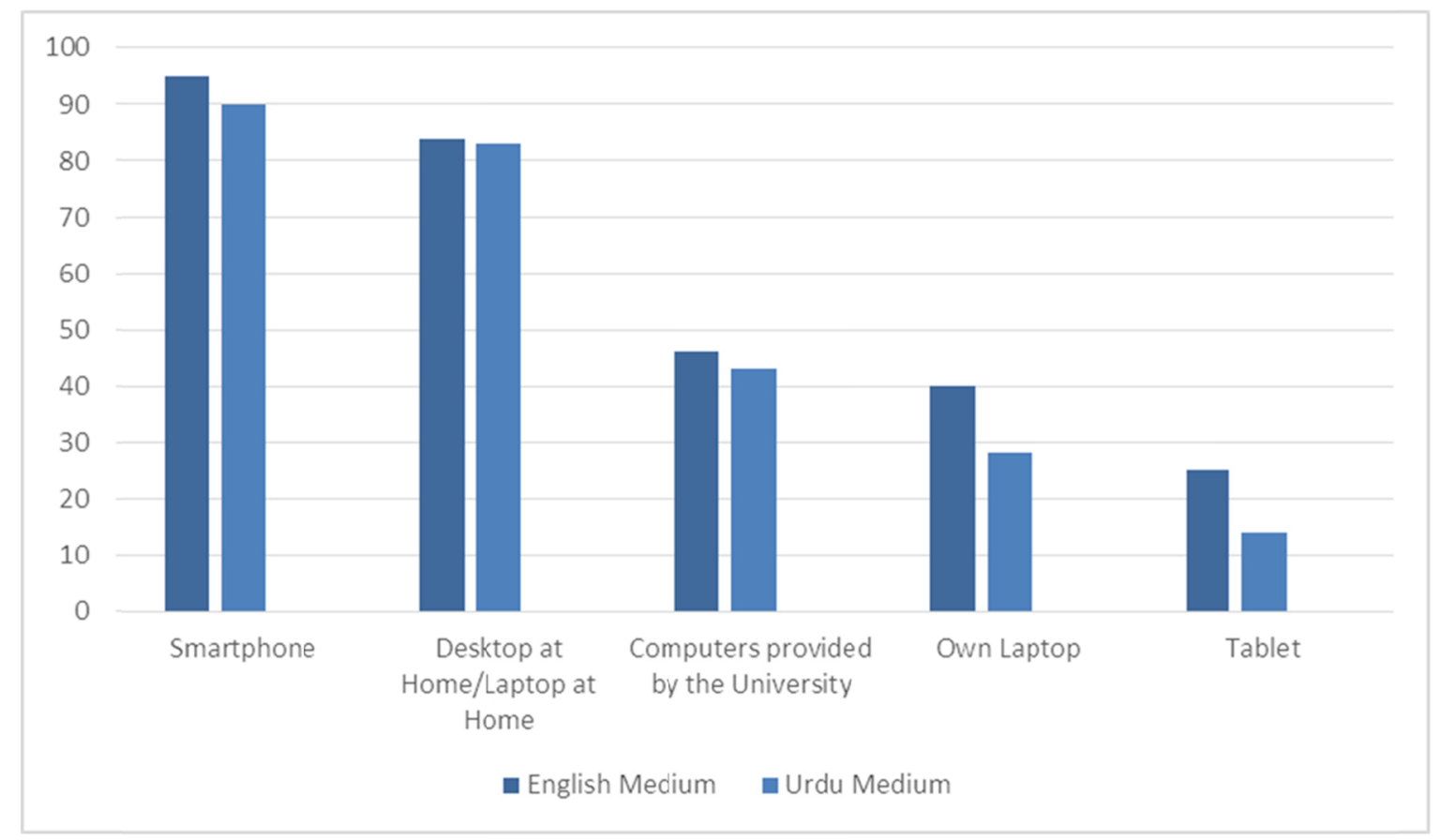

Figure 1. Availability of digital tools to the students

Following the highest accessibility of the smartphones at university, $83 \%$ to $84 \%$ undergraduate students from both English-medium and Urdu-medium schools, also reported accessibility to the desktop computer or laptop at home. However, only $40 \%$ of students from English-medium schools admitted that they bring their own laptops to the university in comparison to just $14 \%$ of students from Urdu-medium schools. Among the five selected digital tools, tablets were observed to be the least common tools among the students. Analysing the accessibility to the digital tools in association with the study majors, it is determined that the undergraduate students of CS have greater access to digital technological tools. Around $21 \%$ of the CS students use smartphones, $46 \%$ are provided computers in university and also bring their own laptops to the university while $38 \%$ have access to the tablets as well.

\subsection{Learning English Language Through Smartphones}

Around $96 \%$ of the undergraduate students reported accessibility to smartphones. 53\% of these students reported using smartphones for at least one or two years while only $50 \%$ of the students revealed using their smartphones for the purpose of studying. $25 \%$ of the respondents were newly introduced to smartphones while the remaining $22 \%$ reported experience of more than two years. Figure 2 below illustrates the general practices of the respondents of using smartphones in English language learning considering gender, the medium of instruction and discipline. 


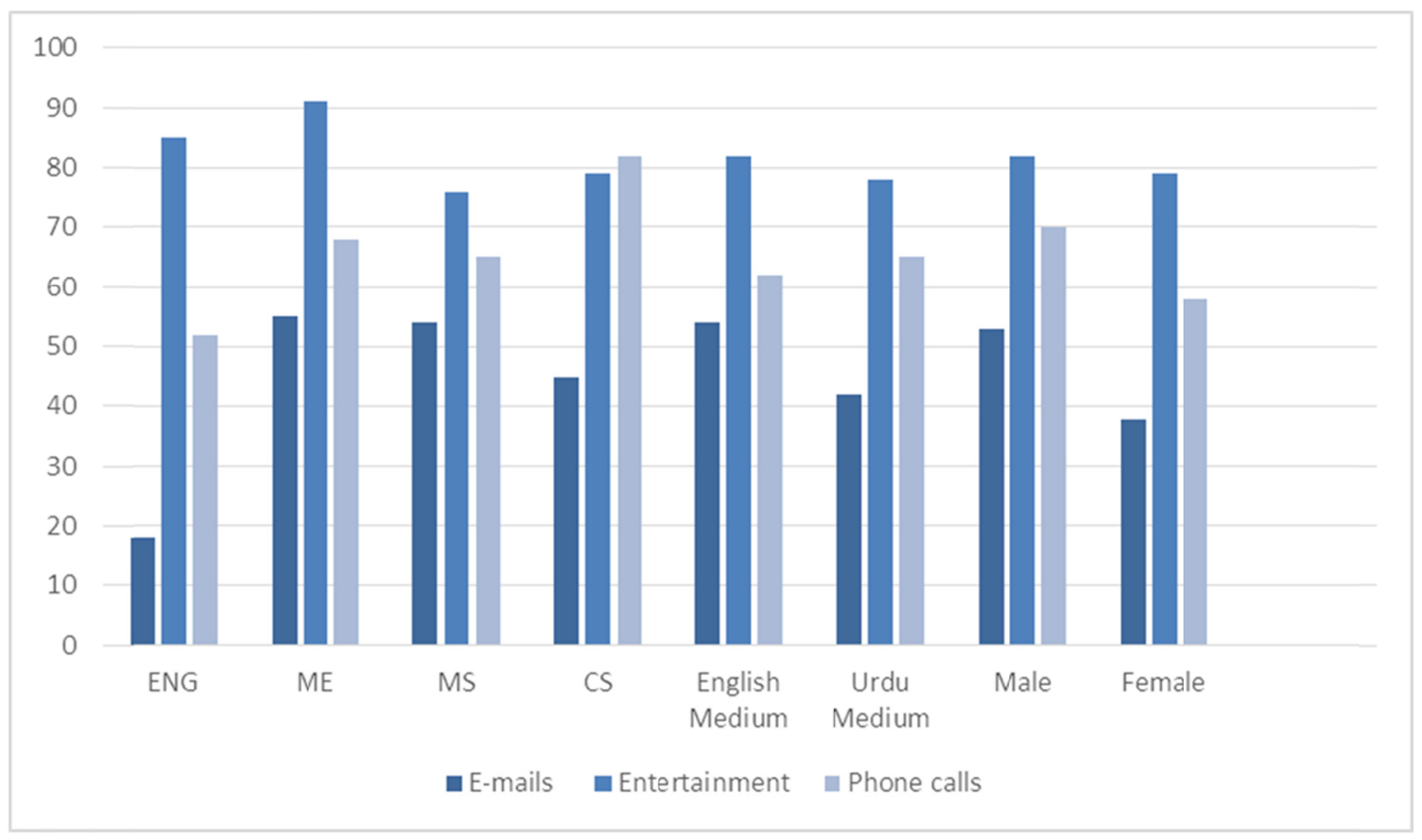

Figure 2. General practices of using smartphones in learning English

\subsection{Improving Reading and Writing Skills Using Smartphones}

For determining the role of smartphones in improving writing and reading skills, different statements were reported by the respondents by means of a four-point Likert scale. The results revealed that more than 50 percent of the students use different smartphone features for improving their English language skills either on a daily or weekly basis. Around $54 \%$ of the respondents reported that they have utilised the memory of their phones for storing reading materials, however, only $33 \%$ were using memory for storing e-books. Furthermore, on a weekly or daily basis, only $54 \%$ of the undergraduate students use text messaging feature, $65 \%$ use smartphone for accessing thesaurus while only $52 \%$ were preferably using Google Translate feature.

In comparison to the $60 \%$ of students from English-medium schools that prefer using a smartphone for the storage of reading materials in English, only 49\% students from Urdu-medium schools use their smartphone memory for this purpose. Similarly, a difference of $61 \%$ and $46 \%$ was also observed in using text messaging feature for learning English among the students with a different medium of education. Furthermore, in comparison to the three study measures with $22 \%$ and $21 \%$ in ENG major, $27 \%$ and $21 \%$ in MS major, $15 \%$ and $11 \%$ in ME major, $52 \%$ of the students from the department of computer science use smartphones memory for reading material while remaining $42 \%$ prefers taking photos. 


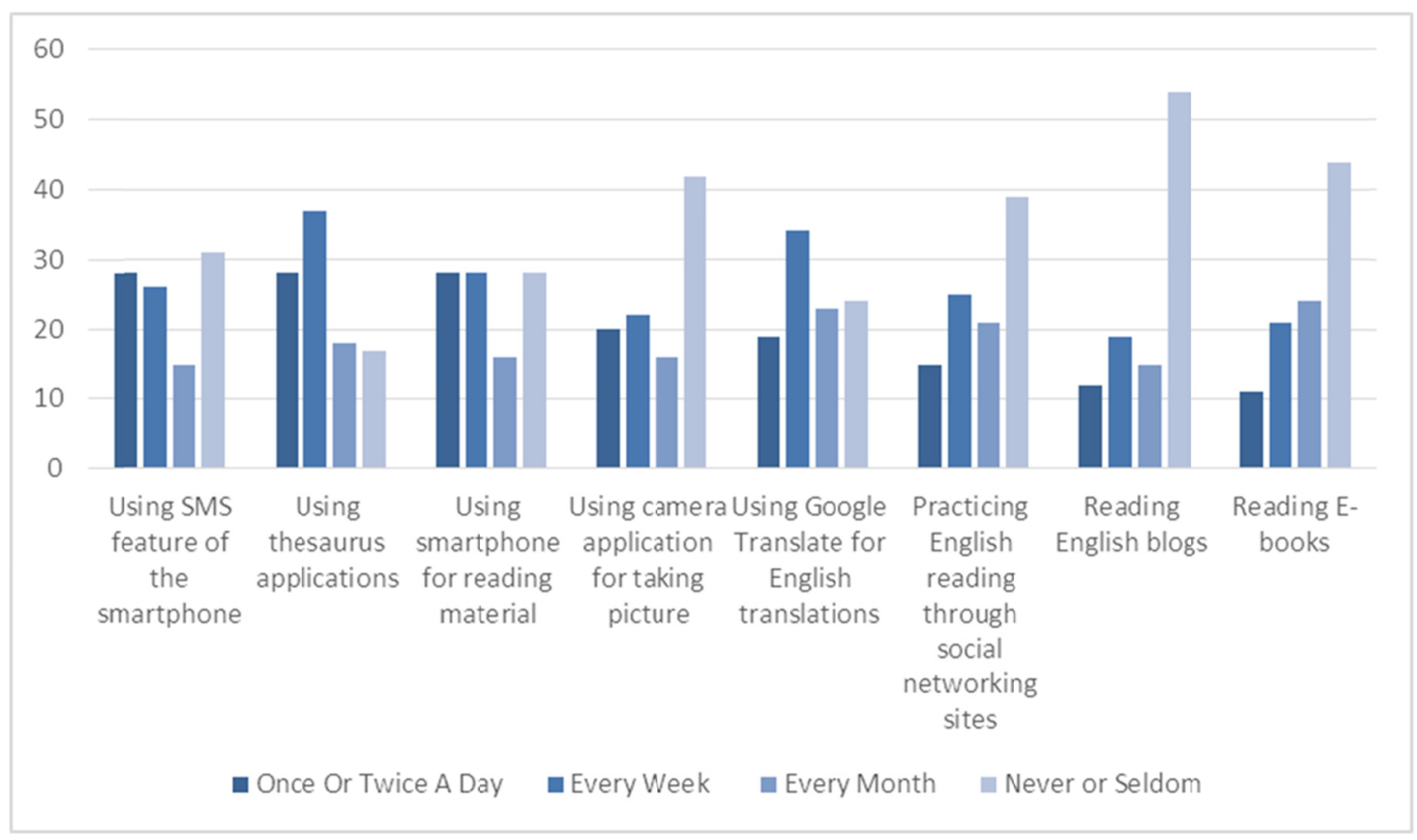

Figure 3. Using smartphones for improving writing and reading skills

\subsection{Preferences for Future}

As indicated by Figure 4 below, the results revealed that altogether $57 \%$ of the respondents were willing to use smartphones for improving their English reading and writing skills in future. Besides this, around $26 \%$ of the students also showed their willingness regarding the productive use of different applications in smartphones. Students have also shown their interest in taking part in training sessions for further improving their English writing as well as reading skills.

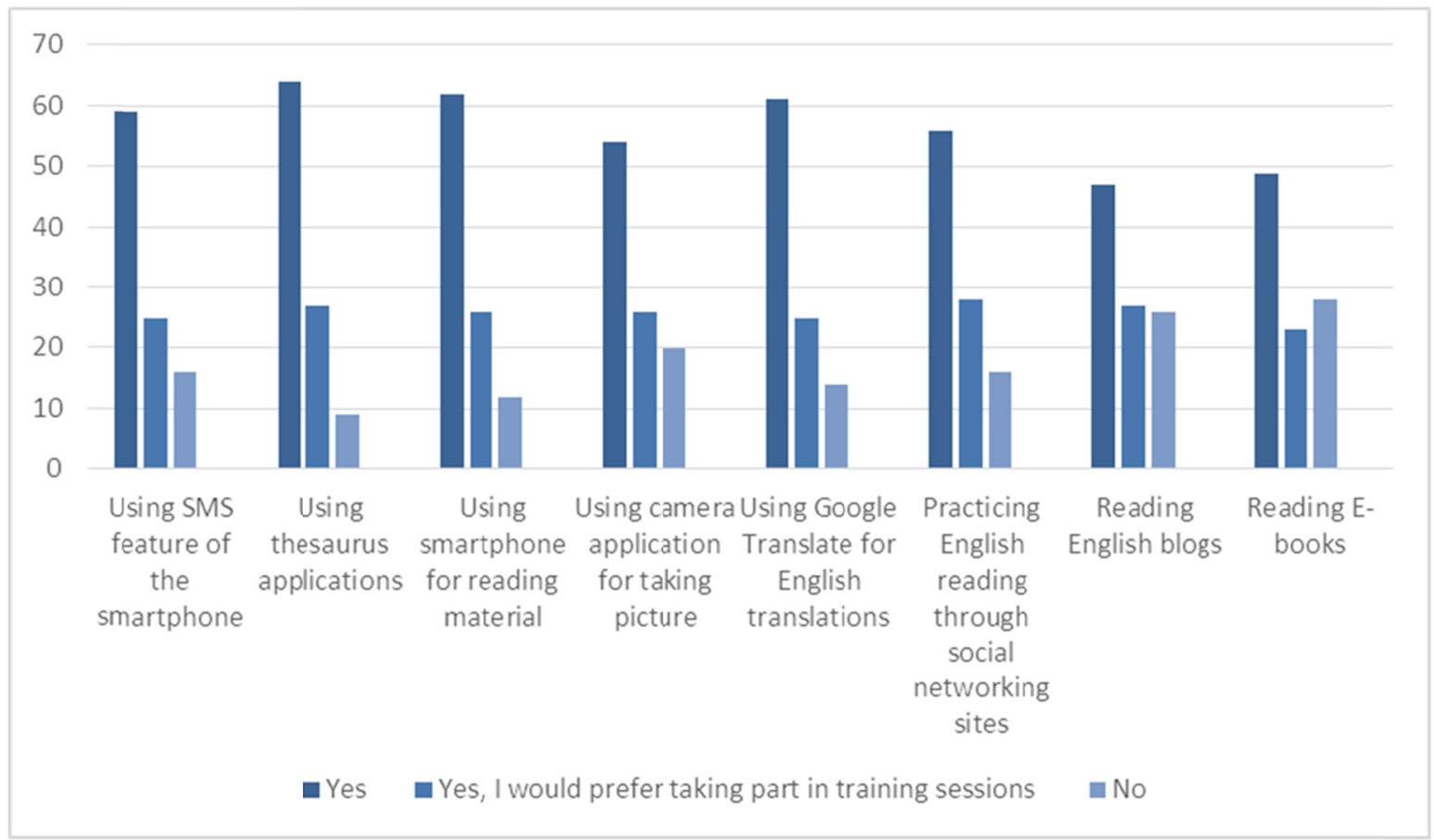

Figure 4. Using smartphones for improving reading and writing skills in future 


\subsection{Improving Speaking and Listening Skills Using Smartphones}

For practising speaking and listening skills every day, only 10 percent of the students revealed using a smartphone. Students also reported not preferring voice recording or calling options. These results indicated that smartphones are still not considered as a suitable option for improving English learning skills. In comparison to the female students, male undergraduate students reported more repeated use of smartphones for different purposes including English reading and listening. On the other hand, the results indicated that $30 \%$ of male students preferred using voice calling for speaking practising compared to only $19 \%$ of female students. Furthermore, 19\% of students from English-medium schools use their smartphone memory for storing listening material compared to only $11 \%$ of students with Urdu as their medium of education in schools. Besides this, in comparison to the selected disciplines, $48 \%$ of CS students focus on different learning practices, at least once or twice a day.

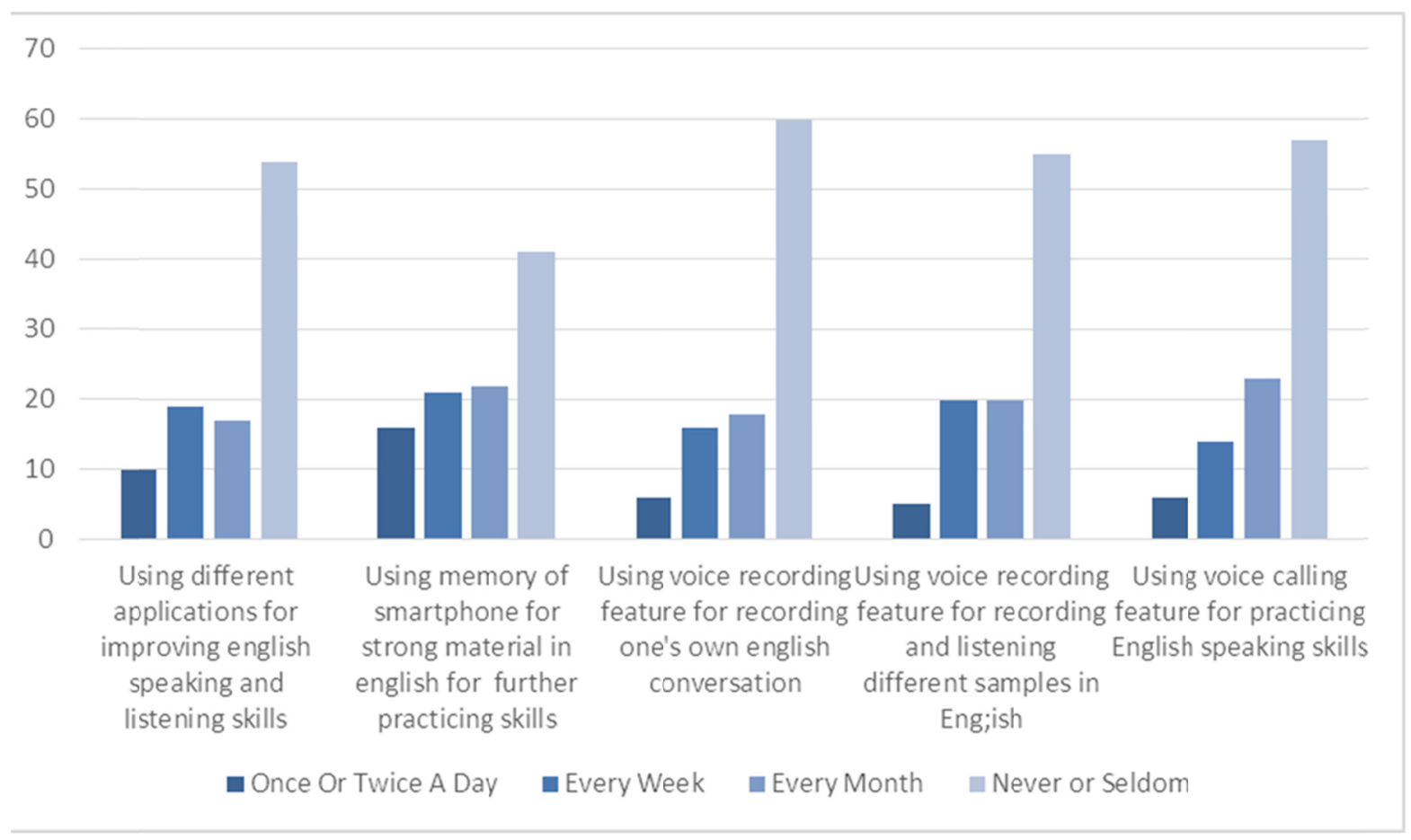

Figure 5. Using smartphones for improving English speaking and listening skills

\subsection{Preferences for Future}

The results revealed that majority of the repondents (51\%) neither considered smartphones as their English learning tool nor they want to use smartphones for improving their English speaking and listening skills. On the other hand, $24 \%$ of students reported their willingness to getting trained for using smartphone applications for enhancing English language skills. Figure 4 and Figure 6 could be compared to determine the differences in opinions of the respondents regarding different English learning skills and their future preferences. The results indicated that in comparison to $49 \%$ students that were willing to use smartphones for improving their speaking and listening skills, $84 \%$ undergraduates admitted their interest in enhancing writing and reading skills in future through smartphones. 


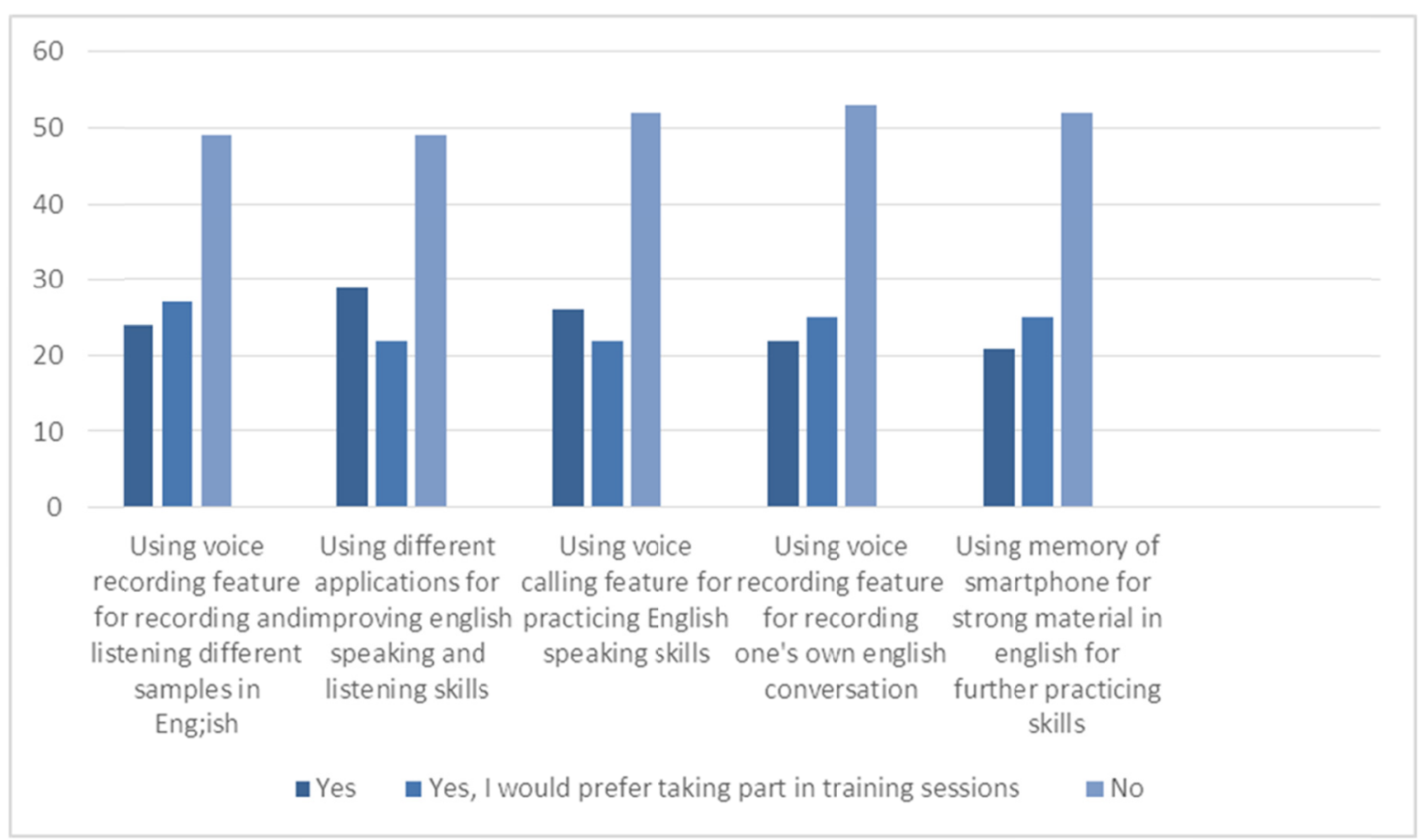

Figure 6. Future preferences for using smartphones for improving English speaking and listening skills

\subsection{Improving English Vocabulary Using Smartphones}

The students were also asked about their interests in using smartphones for enhancing English vocabulary. As illustrated in Figure 7 below, the undergraduate students do not preferably use smartphones for improving their vocabulary. However, as indicated by Figure 8, the students are willing to use their smartphones for this purpose in future.

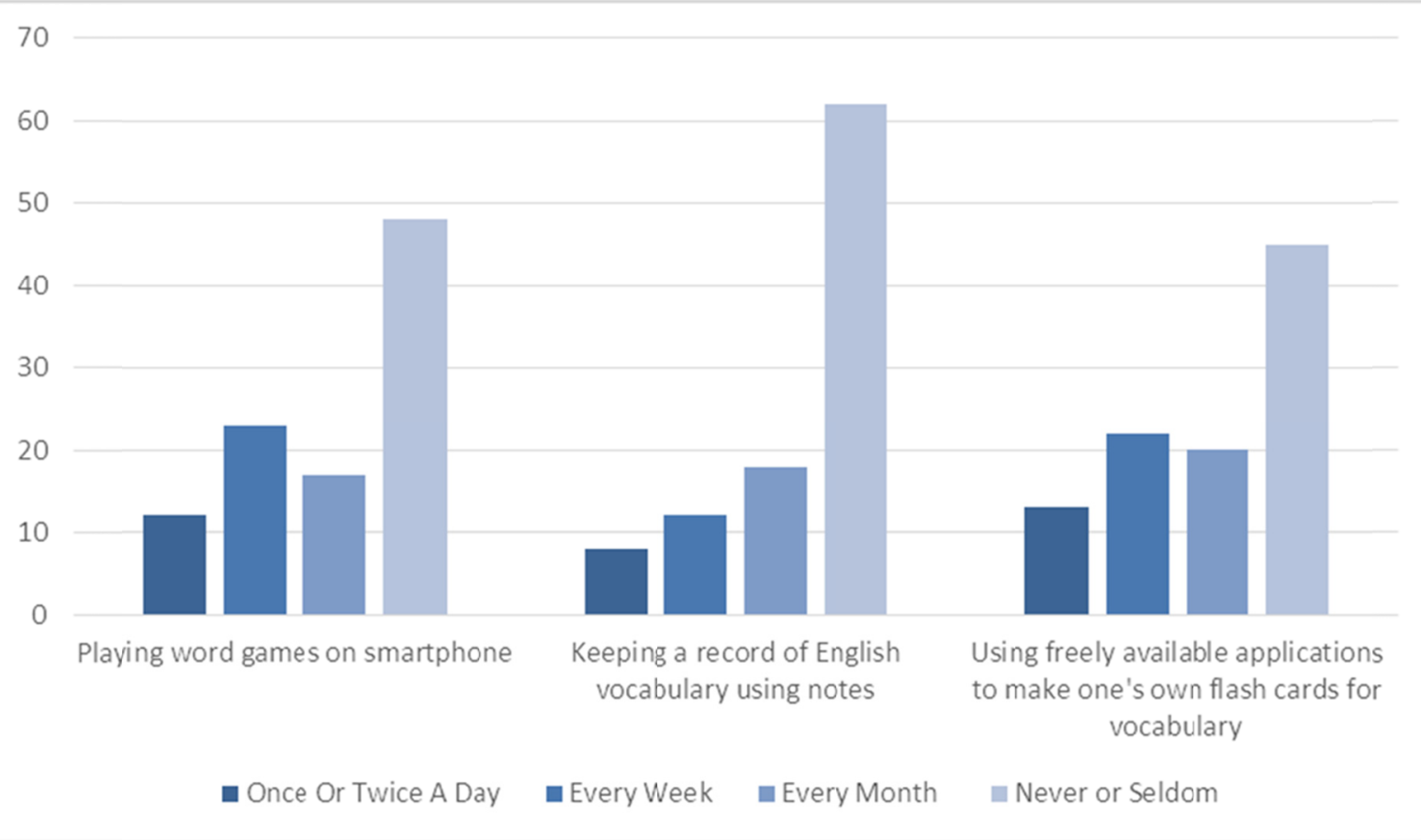

Figure 7. Usage of smartphone for enhancing vocabulary 
In comparison to $8 \%$ on average, the majority of students with CS major (33\%) showed less interest in using smartphones for reading and writing purpose in comparison to listening and speaking. With regards to the mobile applications that can be used for enhancing English listening and speaking skills, Audacity, Listen \& Speak, Speakingpal were the most commonly preferred by the students. Comparatively, only $17 \%$ students with ENG major, 26\% students with MS major, 31\% students with ME major, and 46\% CS major undergraduate students showed their interest in training sessions, specifically for enhancing English speaking and listening skills.

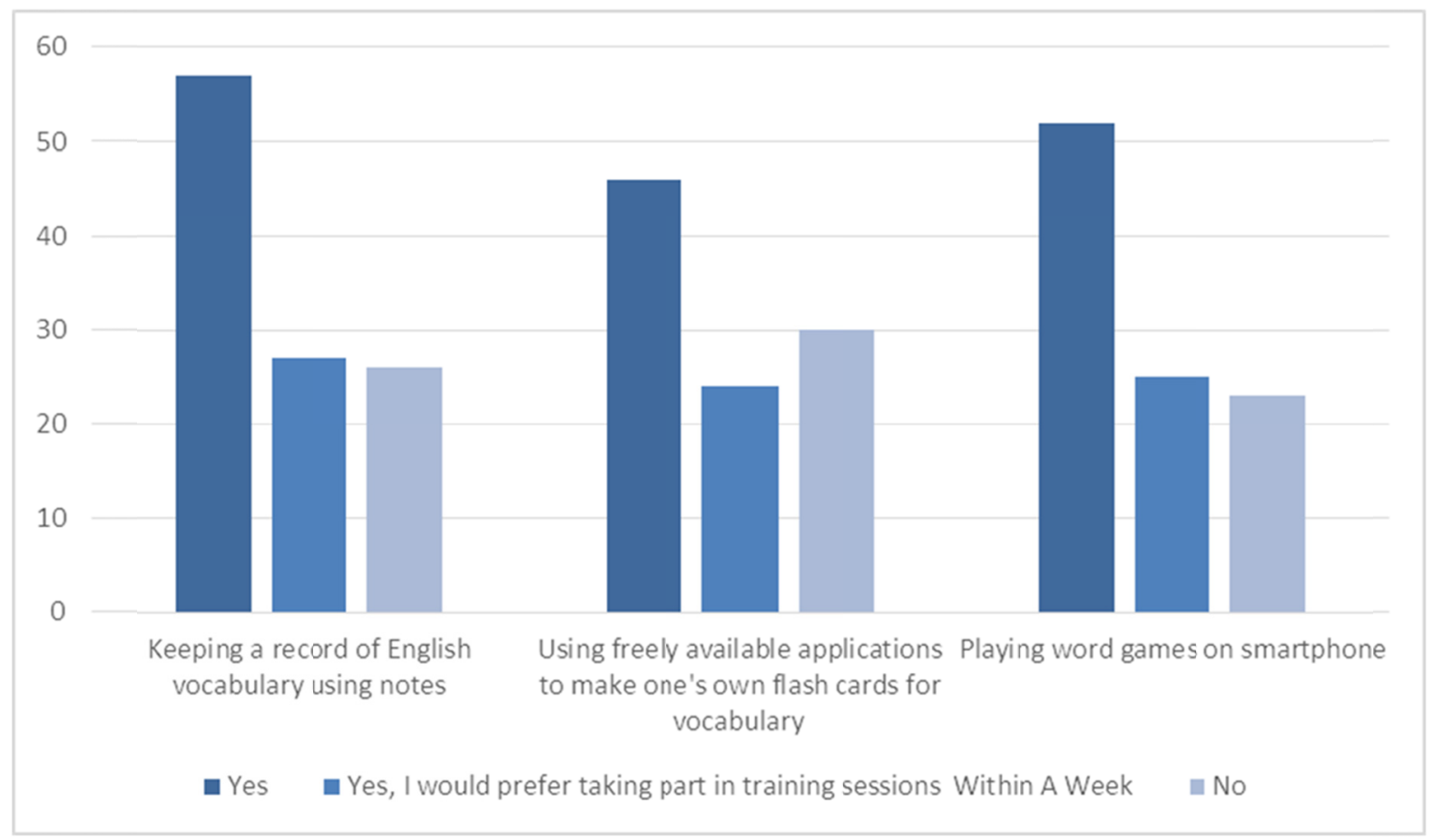

Figure 8. Future preferences for using smartphones

In comparison to the speaking and listening skills, the results revealed that the undergraduate student's considered smartphone a better digital technological tool for improving English vocabulary in future (as illustrated by Figures 6 and 8). As determined, only 49\% of students were interested in using smartphones features for speaking and listening purpose while $76 \%$ expressed their interest in using smartphone applications for improving their vocabulary. However, a comparison of the results illustrated by Figure 4 and Figure 8 revealed that the students preferred using smartphones for enhancing their English vocabulary more than they wanted to utilise the available digital tool for enhancing reading and writing skills in future.

In addition to this, compared with 7\% ME students, 7\% MS students and $12 \%$ ENG students, 30\% of undergraduate CS students reported their interest in using a smartphone for learning English vocabulary. Furthermore, only $29 \%$ of students from Urdu-medium schools reported using notes feature or playing word games on a smartphone in comparison to $43 \%$ of students from English-medium schools. In this way, a major difference among students with different mediums of education in schools was determined in association with learning English vocabulary using several smartphone features and applications.

\section{Discussion}

The aim of the study was to explore the digital technological tools used by the undergraduate students in learning English language at a public sector university in Pakistan. Specifically, the study focused on the determination of the use of digital technological tools in improving English language and its related skills. Also, the future preferences of the respondents regarding use of digital technological tools for improving their English language skills was area of concern. The differences in the preferences of the students in consideration with the variables such as undergraduate level, the medium of education and gender were also determined.

The results of the study revealed that the students at the undergraduate level in Pakistan have accessibility to digital technological tools. Among the five commonly accessible digital tools, as determined through the Digital 
Practices Survey, the most accessible digital tool was determined to be smartphone used by at least $96 \%$ of the survey respondents. Following this, $85 \%$ of students reported having laptops or desktop computers at their home. Ahmed (2017) has also revealed that in the past few years, an increase from $30 \%$ to $50 \%$ is observed in the penetration rate of smartphones in Pakistan. Around $77 \%$ of the smartphones users in Pakistan are between 21 to 25 years of age, however; people from almost all age groups have started using smartphones. The findings also indicated higher accessibility and therefore, smartphones are presenting an opportunity to be used for academic purposes as well. Google has also reported Pakistan to be an emerging country with billions of users in the next few years (Ahmed, 2017).

The findings of the study also revealed that the students also prefer using smartphones as digital technological tools for their on-campus studies indicating restricted use of computers at universities. The reason was the absence of a suitable learning management system in educational institutions and differences in teaching methods. Teaching and methods of teaching have always remained among the neglected areas in Pakistan (Ammar et al., 2015). Hameed and Jan (2016), along with other researchers, have also stated that at the tertiary level of education in the country, the teachers rely more on lecture methods. Therefore, the students are only passive listeners with such teacher-centred teaching at the university level. Around $90 \%$ of the undergraduate students are dissatisfied with teaching and specifically about not using ICT equipment while teaching (Sahito et al., 2017). Less usage of digital tools in institutions is associated with the lack of development of ICT policies and training sessions for teachers in Pakistan (Khokar \& Javaid, 2016). Similarly, the limited use of computers in university might also be as a result of the unavailability of ICT policies.

The previously conducted researches determined gender gap in different areas among students at the undergraduate level in Pakistan. The findings of the studies on other developing countries have also reported the same results (Antonio \& Tuffley, 2014; Zakar, Zakar, Qureshi, \& Fischer, 2014; Abu-Shanab \& Al-Jamal, 2015; Chopra, 2017). The findings of the present study also reported a gender gap in accessibility and usage of digital tools among undergraduate students in Pakistan. In comparison to the female research respondents, male undergraduate students were determined to be using digital tools for learning English language skills more repeatedly. Despite the fact that Pakistan is expected to enter digital revolution, there still exists a major gap among the genders in using digital tools such as social networking sites ( $22 \%$ female and $78 \%$ male). Furthermore, the socio-economic factors also impact the accessibility and use of ICT equipment by the female population in developing countries. Some of these factors are determined to be cultural preferences, insufficient ICT infrastructure in the country and equal accessibility to the ICT and educational opportunities (Singh, 2017). Furthermore, considering ICT for the male population and other such factors is also contributing to the psychological barriers in women resulting in lowering their confidence level and participation in ICT-related activities.

The findings of the study revealed a major difference in accessibility and usage of technology among the students from English-medium and Urdu-medium schools. In comparison to the students with Urdu as their medium of instruction, undergraduate students with English-medium background have greater accessibility to the digital tools both at home and at their educational institutions. Therefore, it can further be stated that English-medium students are using digital tools for both educational and non-educational purposes. However, students with Urdu-medium background were observed to be more interested in playing computer games. The increased use of technology by the students is an indication of the availability and accessibility to the digital facilities at educational institutions.

Major differences in patterns of using digital tools were observed among the undergraduate students with different study groups. As compared to the selected three disciplines ME, MS and ENG, the students with CS major reported greater accessibility and use of digital practices and tools. The findings, however, did not reveal if the accessibility to the digital tools was a result of the needs of the students or their interest. Therefore, it is essential to carry out further investigation as the given strategic solutions of increasing the use of digital tools might not be appropriate for all of the selected disciplines in educational institutions.

Although, majority of the undergraduate students have ease of access to smartphones, however, there are only a few that are using a smartphone for improving their English language skills. With regards to future preferences, around $80 \%$ of students agreed to use smartphones for enhancing English learning skills such as reading and vocabulary. However, the students showed no or less interest in using smartphones for improving their speaking and listening skills.

The results of the study revealed that students from the selected university in Pakistan have accessibility to digital technological tools. In addition, a higher percentage of the students indicating the availability of 
smartphones further discovered that smartphones are accessible to most of the undergraduate students in the country. As the students have expressed their interest in using smartphones for enhancing their English language skills in future, it is essential to further explore the types of applications and technologies to be introduced at the tertiary level of education. Future studies must also focus on the benefits of the implementation of a suitable ICT policy at the tertiary education level as per the interests of the students in using digital technological tools for educational purposes.

\section{Conclusion}

This research regarding the undergraduate students' use of digital technological tools at undergraduate level has several implications in Pakistan as well as other developing countries in the world. The study has some specific implications for higher education institutions operating in the countries and their faculties. The increasing awareness and use of digital technological tools for educational purposes all throughout the world has also led educational institutions in developing countries to include digital equipment for improving the learning of their students. Furthermore, an increase in the use of digital technologies for enhancing the learning of the English language has also been observed. Royo-Vela and Hünermund (2016) also stated that incorporating technology in curriculum and highlighting it as a point of being different from other educational institutions has also become a part of institutional branding. Nevertheless, the adoption of digital tools at the institutional level is still challenging due to the limited resources. Besides the existing digital practices of the students, their future preferences regarding the usage of digital tools would result in maximising the outcomes at both individual and institutional level.

The findings of the study also revealed that the students at the undergraduate level in public sector university in Pakistan do not only have access to the digital technological tools but, at the same time, they are also willing to make the most of technology for learning the English language. As a proper learning management system is not available in Pakistan, smartphones that are available to the majority of the students could be used for the purpose of improving learning through enhanced communications between students and teachers.

The findings of the study also determined the areas that require further detailed examination and investigation. As similar results could not be considered for the other private and public universities in Pakistan, Digital Practices Survey could be carried out at a wider scale. Furthermore, further research could also include the determination of the perspective of teachers regarding the most suitable technology for teaching at the undergraduate level and specifically in classrooms of English language. This would also facilitate in further planning and determination of the ways of dealing with major barriers to integrate technology at educational institutions.

\section{References}

Abu-Shanab, E., \& Al-Jamal, N. (2015). Exploring the gender digital divide in Jordan. Gender, Technology and Development, 19(1), 91-113. https://doi.org/10.1177/0971852414563201

Ahmed, K. (2017, September 26). Pakistan emerges as top market for smartphones. Daily Times. Retrieved from https://dailytimes.com.pk/115257/pakistan-emerges-as-top-market-for- smartphones/

Ammar, A., Naveen, A. L. I., Fawad, A., \& Qasim, K. (2015). Language policy and medium of instruction issue in Pakistan. Acta Linguistica Asiatica, 5(1), 111-124. https://doi.org/10.4312/ala.5.1.111-124

Antonio, A., \& Tuffley, D. (2014). The gender digital divide in developing countries. Future Internet, 6(4), 673-687. https://doi.org/10.3390/fi6040673

Baloch, F. (2014, November). ICT ranking: Pakistan among least connected nations, stands at 142nd place. The Express Tribune. Retrieved from https://tribune.com.pk/story/799668/ict-ranking-pakistan-among-least-connected-nations-stands-at-142nd-p lace/

Bogdan-Martin, D. (2016, April). We must bridge the digital gender divide. The ITUNews Magazine, 5. Retrieved from http://www.itu.int/en/itunews/Documents/2016-04/2016_ITUNews04-en.pdf

Bolluyt. J. (2014, November 28). Why the Internet needs to overcome its language barriers? [Blog post]. Retrieved from http://www.cheatsheet.com/technology/why-the-internet-needs-to-overcome-its-language-barriers.html/?a= viewall

Chopra, P. (2017, June 15). Pakistan bridges the gender divide by embracing a digital economy [Blog post]. Retrieved 
http://blogs.worldbank.org/endpovertyinsouthasia/pakistan-bridges-gender-divide-embracing-digital-econo my

Dahlstrom, E., \& Bichsel, J. (2014). ECAR Study of Undergraduate Students and Information Technology. Educause.

Deng, L., \& Tavares, N. (2015). Exploring university students' use of technologies beyond the formal learning context: A tale of two online platforms. Australasian Journal of Educational Technology, 31(3), 313-327. https://doi.org/10.14742/ajet.1505

Geana, M., \& Greiner, A. (2011). Health information and the digital divide. Journal of Management \& Marketing in Healthcare, 4(2), 108-112. https://doi.org/10.1179/175330311X12943314049538

Gosper, M., Malfroy, J., \& McKenzie, J. (2013). Students' experiences and expectations of technologies: An Australian study designed to inform planning and development decisions. Australasian Journal of Educational Technology, 29(2), 268-282. https://doi.org/10.14742/ajet.127

Hameed, I., \& Jan, T. U. (2016). Comparative study of teaching strategies in the higher education system of Punjab and Khyber Pakhtunkhwa. Gomal University Journal of Research [GUJR], 32(2), 126-134.

Hussain, Z., Bhutto, Z. A., Rai, G., Hussain, M., \& Zaheer, K. (2016). Statistical analysis of network- based issues and their impact on social computing practices in Pakistan. Journal of Computer and Communications, 4(13), 23. https://doi.org/10.4236/jcc.2016.413003

International Telecommunications Union. (2017). ICT facts and figures 2016. Retrieved from http://www.itu.int/en/ITU-D/Statistics/Documents/facts/ICTFactsFigures2017.pdf

Khokhar, A. J., \& Javaid, S. (2016, April). Students and teachers'perceptions of ICT in classroom: Pakistani classroom. Paper presented at the Asian Conference on Technology in the Classroom 2016, Kobe, Japan. Retrieved from https://www.researchgate.net/publication/307476407_Students_and_Teachers_Perceptions_of_ICT_Use_in _Classroom_Pakistani_Classrooms

Khurshid, K., Shah, A. F., \& Reid, N. (2016). Information and communication technology in learning Physics at secondary school level in Pakistan. Bulletin of Education and Research, 38(2), 135-151.

Mascheroni, G., \& Ólafsson, K. (2016). The mobile Internet: Access, use, opportunities and divides among European children. New Media \& Society, 18(8), 1657-1679. https://doi.org/10.1177/1461444814567986

Mueller, J., Wood, E., De Pasquale, D., \& Archer, K. (2011). Students learning with mobile technologies in and out of the classroom. In A. Méndez-Vilas (Ed.), Education in a technological world: communicating current and emerging research and technological efforts (pp. 414-420). Badajoz, Spain: FORMATEX.

Pew Research Center. (2015). Internet seen as positive influence on education but negative influence on morality in emerging and developing nations. Washington, DC: Pew Research Center Studies. Retrieved from http://www.pewglobal.org/files/2015/03/Pew-Research-Center-Technology-Report-FINAL-March-19-2015 1.pdf

Puspitasari, L., \& Ishii, K. (2016). Digital divides and mobile Internet in Indonesia: Impact of smartphones. Telematics and Informatics, 33(2), 472-483. https://doi.org/10.1016/j.tele.2015.11.001

Royo-Vela, M., \& Hünermund, U. (2016). Effects of inbound marketing communications on HEIs' brand equity: the mediating role of the student's decision-making process. An exploratory research. Journal of Marketing for Higher Education, 26(2), 143-167. https://doi.org/10.1080/08841241.2016.1233165

Sahito, Z., Siddiqui, A., Khawaja, M., Shaheen, A., Saeed, H., \& Laghari, S. H. (2017). Teaching of Remedial English and the Problems of the Students: A Case of University of Sindh, Jamshoro, Sindh, Pakistan. World Journal of English Language, 7(1), 1-10. https://doi.org/10.5430/wjel.v7n1p1

Salam, S., Jianqiu, Z., Pathan, Z. H., \& Lei, W. (2017, December). Strategic barriers in the effective integration of ICT in the public schools of Pakistan (pp. 169-172). Proceedings of the 2017 International Conference on Computer Science and Artificial Intelligence. Jakarta, Indonesia: ACM. https://doi.org/10.1145/3168390.3168422

Singh, S. (2017). Bridging the gender digital divide in developing countries. Journal of Children and Media, 11(2), 245-247. https://doi.org/10.1080/17482798.2017.1305604

Swanson, J. A., \& Walker, E. (2015). Academic versus non-academic emerging adult college student technology 
use. Technology, Knowledge and Learning, 20(2), 147-158. https://doi.org/10.1007/s10758-015-9258-4

The Nation. (2016). Pakistan to have 40m smartphones by end of 2016. Retrieved from http://nation.com.pk/30-Oct-2016/pakistan-to-have-40m-smartphones-by-end-of-2016

World Economic Forum. (2016). Global gender gap report. Retrieved from http://reports.weforum.org/global-gender-gap-report-2016/

W3Techs. (2017). Usage of content languages for website. Retrieved from https://w3techs.com/technologies/overview/content_language/all

Zakar, R., Zakar, M. Z., Qureshi, S., \& Fischer, F. (2014). Harnessing information technology to improve women's health information: Evidence from Pakistan. BMC Women's Health, 14(1), 105. https://doi.org/10.1186/1472-6874-14-105

\section{Copyrights}

Copyright for this article is retained by the author, with first publication rights granted to the journal.

This is an open-access article distributed under the terms and conditions of the Creative Commons Attribution license (http://creativecommons.org/licenses/by/4.0/). 